\title{
Lack of Interaction Between the Peptidomimetic Substrates Captopril and Cephradine
}

\author{
David R. Foster, PharmD, Shiyin Yee, PhD, Barry E. Bleske, PharmD, Peggy L. Carver, \\ PharmD, Michael J. Shea, MD, Sujatha S. Menon, PhD, Chandrasekharan \\ Ramachandran, MS, Lynda S. Welage, PharmD, Gordon L. Amidon, PhD
}

Intestinal peptide transporters, including hPEPT1, facilitate the absorption of cephalosporins and angiotensinconverting enzyme inhibitors, and have been investigated as a means to improve oral drug absorption. Renal peptide transporters including hPEPT2, may also facilitate renal reabsorption of such compounds. In vitro and animal studies suggest that co-administration of peptidomimetic compounds may alter oral pharmacokinetics, although this has not been well studied in humans. The purpose of this study was to determine whether co-administration of the hPEPT substrates captopril and cephradine alters the oral pharmacokinetics of either agent. Nine healthy male volunteers received a single oral 25-mg dose of captopril, a single oral 500-mg dose of cephradine, or concurrent ingestion of captopril and cephradine in a cross-over manner. Venous blood samples were taken and captopril and cephradine pharmacokinetics were determined using noncompartmental analyses. No significant differences were observed in captopril or cephradine pharmacokinetics when administered together as compared to each agent alone (a marginal decrease in $C_{\max }$ was observed for both captopril and cephradine during co-administration [5-15\%]; however, differences were not statistically significant). The results of our study suggest that hPEPT1 and hPEPT2 are unlikely to contribute to clinically important drug interactions in humans.

Keywords: Cephalosporin; ACE-inhibitor; peptide transport; drug interaction; hPEPT1

Journal of Clinical Pharmacology, 2009;49:360-367 (C) 2009 the American College of Clinical Pharmacology
$\mathbf{T}$ he disposition of many xenobiotics is highly dependent on the activity of intestinal mucosal transporters. ${ }^{1}$ Efflux transporters have been studied extensively, and can limit the systemic availability of a large range of compounds. ${ }^{2,3}$ In contrast, the role of nutrient transporters in facilitating drug absorption and tissue delivery has been investigated less comprehensively. It is well recognized, however,

\footnotetext{
From Department of Pharmacy Practice, Purdue University, School of Pharmacy and Pharmaceutical Sciences, Indianapolis, IN (Dr Foster), Shiyin Yee Inc., Cupertino, CA (Dr Yee), College of Pharmacy, University of Michigan, and Department of Pharmacy Services, University Hospital, Ann Arbor, MI (Dr Bleske, Dr Carver, Dr Welage), Department of Internal Medicine, Medical School, University of Michigan, Ann Arbor, MI (Dr Shea), Pfizer, Inc., New London, CT (Dr Menon), and College of Pharmacy, University of Michigan, Ann Arbor, MI (Dr Ramachandran, Dr Amidon). Submitted for publication August 13, 2008; revised version accepted November 15, 2008. Address for correspondence: Gordon L. Amidon, PhD, Department of Pharmaceutical Sciences, The University of Michigan College of Pharmacy, 428 Church Street, Ann Arbor, MI, 48109-1065.E-mail: glamidon@umich.edu.

DOI: $10.1177 / 0091270008329554$
}

that multiple nutrient transporter systems involved in the active absorption of peptides, glucose and other carbohydrates, amino acids, organic anions, organic cations, bile acids, and other nutrients are abundant in the intestinal mucosa, and that many of these transporters may also affect the absorption of exogenously administered xenobiotics. ${ }^{1,4-6}$

In the small intestine, di- and tripeptides are absorbed through carrier-mediated processes by peptide transporters, including the human oligopeptide transporter, hPEPT1 (SLC15A1). hPEPT1 is an $\mathrm{H}^{+}$/ peptide symporter located in the brush border membrane of the small intestine which has broad substrate specificity. ${ }^{1,7,8}$ In addition to transporting oligopeptides, hPEPT1 also mediates the membrane transport of a diverse range of xenobiotics, including peptidomimetic drugs. Substrates for hPEPT1 include $\beta$-lactam antibiotics, aminocephalosporins with a free $\alpha$-amino group, antiviral prodrugs (eg, valacyclovir, valgancyclovir), and angiotensinconverting enzyme (ACE) inhibitors. ${ }^{8-10}$ Peptide transporters are also present in other organs such as 
the kidneys, central nervous system, and respiratory tract. ${ }^{11-13}$ The presence of hPEPT1 and the related renal oligopeptide transporter, hPEPT2, in the kidneys may play a role in the renal reabsorption of peptidomimetics. ${ }^{14-16}$

Drug interactions occurring as a result of coadministration of hPEPT1 substrates in humans are not well studied. These interactions are of interest, because there are a large number of hPEPT1 drug substrates, and hPEPT1 is actively targeted as a means to improve oral drug absorption. Therefore, it would be desirable if co-administration of hPEPT1 substrates did not result in interactions. However, co-administration of transporter substrates may result in competition for transporters, and could affect the intestinal absorption and disposition of the substrates. To this end, competitive inhibition of hPEPT1-mediated transport of substrates, including cephalosporin antibiotics and ACE inhibitors, has been described in cultured epithelial cell models, excised membrane vesicles, and in situ animal models. ${ }^{17-28}$ Similarly, competitive inhibition of peptide transport has been demonstrated in renal brush border membrane vesicles, and suggested in animal models. ${ }^{15}$ Based on these data, one may anticipate that drug-drug and/or drug-nutrient interactions involving peptide transporters are possible in humans. The purpose of this study was to assess the potential interaction between 2 peptidomimetic hPEPT1 substrates, the aminocephalosporin cephradine, and the ACE inhibitor captopril, in humans. Specifically, we hypothesized that competition of captopril and cephradine for intestinal transporters may result in impaired and/or delayed absorption of either or both agents.

\section{METHODS}

\section{Human Subjects}

Nine healthy male volunteers were included in this study. Subjects were deemed healthy by physical examination and serum chemistries. The mean weight of the subjects was $75 \mathrm{~kg}$ (range, 64-91 kg), and all subjects were within $20 \%$ of their ideal body weight. The mean age of the subjects was 26 years (range, 20-32 years). All subjects were nonsmokers, had refrained from other medications (prescription and over-the-counter) for 1 week before study entry, and had no history of hypersensitivity to cephalosporins or ACE inhibitors. All subjects provided written informed consent before participation, and all procedures were approved by the University of Michigan Institutional Review Board before initiating the study.
A randomized, open label, 3-way, cross-over design was used. The 3 study phases consisted of: (1) Phase A: a single 25-mg oral dose of captopril (Capoten ${ }^{\circledR}$, Bristol-Myers Squibb, New York, NY); (2) Phase B: a 500-mg oral dose of cephradine (Velosef®, Bristol-Myers Squibb, New York, NY) coadministered with a 25-mg oral dose of captopril, and (3) Phase C: a single 500-mg oral dose of cephradine. All medications were from the same lot. In each phase, subjects were instructed to fast overnight (approximately 10 hours) before oral administration of the assigned study drug treatment, which was administered with $240 \mathrm{~mL}$ of water. During each phase, subjects were required to remain in a sitting position for 4 hours after receiving the study medication. Each study phase was separated by a minimum of 2 weeks. Standard meals were provided 4 and 9 hours after dosing. Venous blood samples (10 $\mathrm{mL}$ ) were collected immediately before dosing, and at $0.25 .0 .5,0.75,1,1.25,1.5,2,2.5,3,4,6,8,9$, and 10 hours after drug administration during each treatment phase. Samples were centrifuged at $4^{\circ} \mathrm{C}$, and the plasma samples for captopril assays were treated with excess n-ethylmaleimide (NEM) to form a stable captopril-NEM adduct and then stored at $-20^{\circ} \mathrm{C}$ until time of analysis.

\section{Analytical Methods}

After an oral dose, captopril is present in the plasma as unchanged drug (approximately $50 \%$ of dose) and a dimeric disulfide metabolite (approximately $10 \%$ of dose). Therefore, plasma concentrations of both total and unchanged captopril were determined as described previously, with some minor modifications. ${ }^{29,30}$ In brief, the 4-ethoxy proline analogue of captopril served as the internal standard. After extracting the excess NEM with $5 \mathrm{~mL}$ of ethyl acetate, the aqueous phase was acidified with 500 $\mu \mathrm{L}$ of $2 \mathrm{M} \mathrm{HCl}$, to which $2 \mathrm{~g}$ of sodium chloride was added, vortexed and extracted with $10 \mathrm{~mL}$ of purified ethyl acetate. The ethyl acetate layer was evaporated to dryness under nitrogen in a $40-50^{\circ} \mathrm{C}$ water bath. The dry extract was treated with $100 \mu \mathrm{L}$ of hexafluoro-2-propanol and $50 \mu \mathrm{L}$ of trifluoroacetic anhydride for 15 minutes at $60^{\circ} \mathrm{C}$, evaporated under $\mathrm{N}_{2}$ and the dry residue reconstituted with ethylacetate: N-methyl formamide (1:1). An aliquot containing the hexafluorisopropyl esters of the NEM adducts of captopril and the internal standard was injected into a gas chromatography-mass spectrophotometer assembly. To determine total captopril content, tributylphosphine $(20 \% \mathrm{v} / \mathrm{v})$ was added to the plasma samples, vortexed and heated for 60 minutes at $50^{\circ} \mathrm{C}$. 
Excess tributylphosphine was extracted with $5 \mathrm{~mL}$ of ethyl acetate. Subsequently $0.2 \mathrm{~mL}$ of NEM (10 $\mathrm{mg} / \mathrm{mL}$ ) was added to the aqueous plasma layer which was then allowed to stand for 15 minutes at room temperature. Further extraction, derivatization and GC analysis were performed as outlined for unchanged captopril. Standard curves were prepared daily and constructed from spiked blank plasma containing $0-500 \mathrm{ng} / \mathrm{mL}$ of captopril, $500 \mathrm{ng}$ of internal standard and $100 \mu \mathrm{L}$ of NEM. For this assay, the lower limit of detection of captopril in plasma was $2 \mathrm{ng} / \mathrm{mL}$, and the inter-day coefficient of variation was $7 \%$.

Cephradine concentrations were determined using high-performance liquid chromatography using methods adapted from Lidgren and colleagues. ${ }^{31}$ Briefly, the analytical column was a $\mu$ Bondpak C18 column, the mobile phase was $13 \%$ acetonitrile in $0.02 \mathrm{M} \mathrm{NaH}_{2} \mathrm{PO}_{4}(\mathrm{pH}$ 5), the flow rate of the mobile phase was $1.6 \mathrm{~mL} / \mathrm{min}$, and absorbance was measured at $262 \mathrm{~nm}$. For the cepharadine assay, the intra-day coefficient of variation for the assay was $<6 \%$ over the concentration range of 3 to $20 \mu \mathrm{g} / \mathrm{mL}$, and the inter-day coefficient of variation was $<5 \%$ over the same concentration range.

\section{Pharmacokinetic Analysis}

Conventional noncompartmental pharmacokinetic analyses were performed. ${ }^{32}$ Maximum plasma concentration $\left(\mathrm{C}_{\max }\right)$, and time to maximum plasma concentration $\left(\mathrm{T}_{\text {max }}\right)$, were determined by visual inspection of the data. The apparent elimination constant $\left(\mathrm{k}_{\mathrm{e}}\right)$ was calculated based on linear regression of the log-linear terminal phase of the plasma concentration time curve. Elimination half-life was determined as $\left(\ln 2 / \mathrm{k}_{\mathrm{e}}\right)$. The area under the plasma concentration versus time curve $\left(\mathrm{AUC}_{\text {inf }}\right)$ was calculated using the trapezoidal rule and extrapolated to infinity based on $\mathrm{C}_{n} / \mathrm{k}_{\mathrm{e}}$, were $\mathrm{C}_{\mathrm{n}}$ is the last measureable concentration. Additionally, partial areas under the plasma concentration versus time curve in the first hour after administration $\left(\mathrm{AUC}_{0-1}\right)$ were calculated to better characterize changes in absorption (ie, while absorption was the dominant process).

\section{Statistical Analyses}

Statistical analyses were performed to explore potential differences in pharmacokinetic parameters between study phases using 2-tailed, paired t tests. Data are presented as mean \pm standard deviation (SD). For all tests, $P<.05$ was considered to be significant.

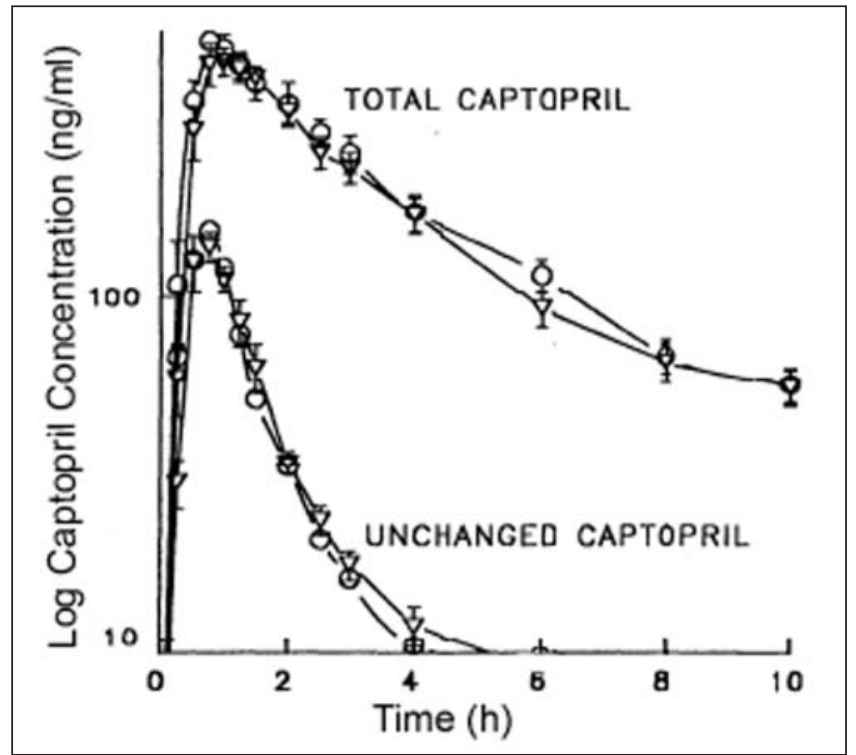

Figure 1. Captopril unchanged and total captopril plasma concentration versus time curves. Data represent mean $\pm S D$ for each time point. $\bigcirc$, captopril alone; $\nabla$, captopril with cephradine.

\section{RESULTS}

\section{Noncompartmental Analyses}

Mean plasma concentrations of unchanged and total captopril versus time curves after oral administration of captopril alone or after co-administration of cephradine with captopril to human subjects are shown in Figure 1. The relevant pharmacokinetic parameters for unchanged and total captopril during phase A (captopril alone) and Phase B (captopril coadministered with cephradine) are summarized in Table I. No significant differences were noted in the pharmacokinetics of either unchanged or total captopril when administered alone or in combination with cephradine. Of interest, the $\mathrm{C}_{\max }$ for both unchanged and total captopril was slightly decreased when captopril was co-administered with cephradine as compared to when it was administered alone and likewise the $\mathrm{T}_{\max }$ was slightly delayed. Detectible total captopril concentrations were still present at the end of the sampling (10 hours); our sampling strategy captured $89.1 \%$ of the mean $\mathrm{AUC}_{0-\text { infinity }}$ for total captopril alone, and $88.1 \%$ of the mean $\mathrm{AUC}_{0 \text {-infinity }}$ for total captopril with cephradine.

Cephradine mean plasma concentration versus time curves are similar after oral administration of cephradine alone or after co-administration of cephradine with captopril (Figure 2). The pharmacokinetic parameters for cephradine when administered alone 
Table I Total Captopril and Unchanged Captopril Pharmacokinetic Parameters From Noncompartmental Analysis ${ }^{a}$

\begin{tabular}{|c|c|c|c|}
\hline & Parameter & Captopril Alone & Captopril with Cephradine \\
\hline Unchanged captopril & $\begin{array}{l}\mathrm{C}_{\max }(\mathrm{ng} / \mathrm{mL}) \\
\mathrm{T}_{\max }(\mathrm{h}) \\
\mathrm{AUC}_{\text {inf }}\left(\mathrm{mcg} / \mathrm{h}^{*} \mathrm{~L}\right) \\
\mathrm{f}(0-1) \\
\mathrm{t}_{1 / 2}(\mathrm{~h}) \\
\mathrm{Cl} / \mathrm{F}(\mathrm{L} / \mathrm{h} / \mathrm{kg})\end{array}$ & $\begin{aligned} 177.3 & \pm 46.8 \\
0.67 & \pm 0.18 \\
231.97 & \pm 54.18 \\
0.41 & \pm 0.09 \\
1.97 & \pm 0.87 \\
1.21 & \pm 0.27\end{aligned}$ & $\begin{aligned} 153.0 & \pm 48.0 \\
0.72 & \pm 0.24 \\
221.86 & \pm 68.10 \\
0.37 & \pm 0.09 \\
1.88 & \pm 1.02 \\
1.34 & \pm 0.51\end{aligned}$ \\
\hline Total captopril & $\begin{array}{l}\mathrm{C}_{\max }(\mathrm{ng} / \mathrm{mL}) \\
\mathrm{T}_{\max }(\mathrm{h}) \\
\mathrm{AUC}_{\text {inf }}\left(\mathrm{mcg} / \mathrm{h}^{*} \mathrm{~L}\right) \\
\mathrm{f}(0-1) \\
\mathrm{t}_{1 / 2}(\mathrm{~h}) \\
\mathrm{Cl} / \mathrm{F}(\mathrm{L} / \mathrm{h} / \mathrm{kg})\end{array}$ & $\begin{aligned} 614.93 & \pm 150.75 \\
0.78 & \pm 0.24 \\
2171.23 & \pm 560.01 \\
0.16 & \pm 0.03 \\
2.95 & \pm 0.36 \\
0.13 & \pm 0.03\end{aligned}$ & $\begin{aligned} 580.6 & \pm 135.0 \\
0.94 & \pm 0.21 \\
1987.20 & \pm 585.69 \\
0.14 & \pm 0.03 \\
2.93 & \pm 0.27 \\
0.14 & \pm 0.03\end{aligned}$ \\
\hline
\end{tabular}

$\mathrm{C}_{\max }$, maximum plasma concentration; $\mathrm{T}_{\max }$, time to maximum plasma concentration $\mathrm{AUC}_{\text {inf }}$, area under the plasma concentration versus time curve extrapolated to infinity; f (0-1), ratio of $\mathrm{AUC}_{0-1} / \mathrm{AUC}_{\text {inf }}$; $\mathrm{t}_{1 / 2}$, half-life; Cl/F, oral clearance $(\mathrm{L} / \mathrm{h} / \mathrm{kg})$.

${ }^{a}$ Values are mean \pm SD. $P>.05$ for all parameters when captopril alone is compared with captopril with cephradine.

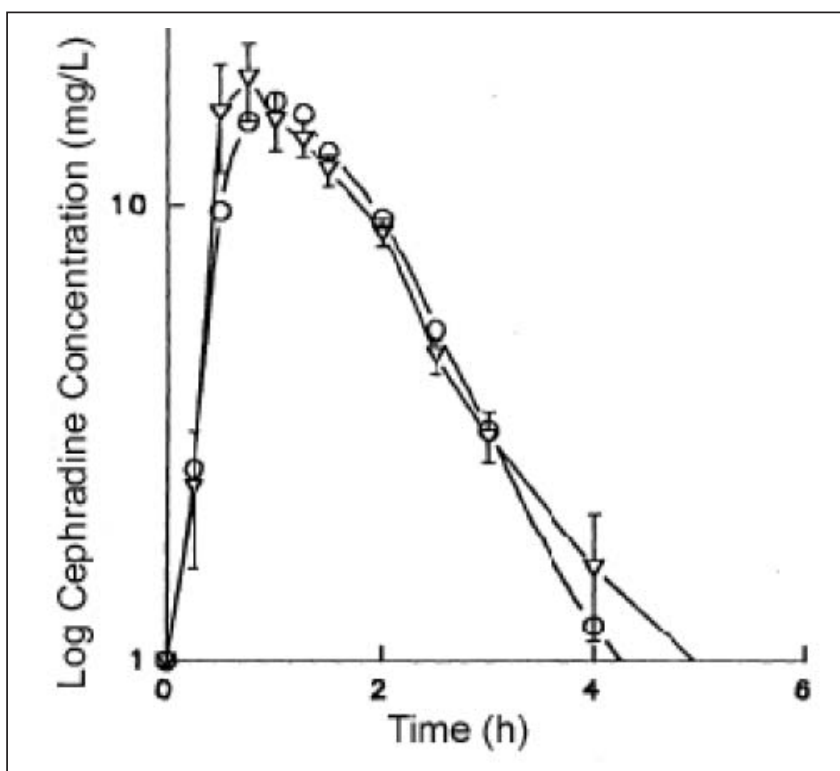

Figure 2. Cephradine plasma concentration versus time curves. Data represent mean $\pm S D$ for each time point. $\bigcirc$, cephradine alone; $\nabla$, cephradine with captopril.

(phase C) or in combination with captopril are listed in Table II. Captopril administration resulted in a marginal decrease in the $\mathrm{C}_{\max }$ of cephradine; the mean percent decrease in $\mathrm{C}_{\max }$ was $10.0 \pm 15.6$, although this difference only approached significance $(P=.053)$. Figure 3 shows the effects of captopril administration on cephradine $\mathrm{C}_{\max }$ for individual subjects. In 6 of the 9 subjects, captopril administration was associated with a decrease in cephradine $\mathrm{C}_{\max }$, whereas cephradine $\mathrm{C}_{\max }$ was higher with co-administration of captopril in 3 subjects. Co-administration of captopril did not significantly delay cephradine absorption, nor did it significantly impair the extent of cephradine absorption, as indicated by $\mathrm{T}_{\max }$, $\mathrm{f}(0-1)$, and $\mathrm{AUC}_{\text {inf }}$ values (Table II).

\section{DISCUSSION}

The oligopeptide transporter hPEPT1 plays a role in the active absorption of several drugs, and has been suggested as a potential means to improve the oral absorption of drugs in the drug design process. Despite the pharmacological importance of hPEPT1, little is known about the propensity of hPEPT1 (and the related renal transporter, hPEPT2) to cause drug interactions in humans. In this study, we observed no clinically significant interaction when 2 peptidomimetic substrates, captopril and cephradine, were co-administered to healthy human subjects by means of the oral route. Co-administration slightly decreased the mean peak plasma concentration of cephradine, however, this difference only approached statistical significance. Although this could indicate competition for uptake by peptide transporters in the intestine, no other pharmacokinetic parameters supported such an interaction; specifically, no significant changes in $\mathrm{T}_{\max }, \mathrm{AUC}_{\text {inf }}$, or partial AUC's were observed with captopril co-administration. Both captopril and cephradine are eliminated, at least in 
Table II Cephradine Pharmacokinetic Parameters From Noncompartmental Analysis ${ }^{\mathrm{a}}$

\begin{tabular}{lcc}
\hline \hline Parameter & $\begin{array}{c}\text { Cephradine } \\
\text { Alone }\end{array}$ & $\begin{array}{c}\text { Cephradine } \\
\text { With Captopril }\end{array}$ \\
\hline $\mathrm{C}_{\max }(\mathrm{mg} / \mathrm{L})$ & $23.33 \pm 8.28$ & $20.25 \pm 5.33$ \\
$\mathrm{~T}_{\max }(\mathrm{h})$ & $0.917 \pm 0.375$ & $1.00 \pm 0.280$ \\
$\mathrm{AUC}_{\text {inf }}(\mathrm{mg} / \mathrm{h} * \mathrm{~L})$ & $35.49 \pm 8.87$ & $34.66 \pm 11.12$ \\
$\mathrm{f}(0-1)$ & $0.31 \pm 0.17$ & $0.27 \pm 0.14$ \\
$\mathrm{t}_{1 / 2}(\mathrm{~h})$ & $1.26 \pm 0.76$ & $1.31 \pm 1.75$ \\
$\mathrm{Cl} / \mathrm{F}(\mathrm{L} / \mathrm{h} / \mathrm{kg})$ & $0.2 \pm 0.05$ & $0.2 \pm 0.06$ \\
\hline
\end{tabular}

$\mathrm{C}_{\max }$, maximum plasma concentration; $\mathrm{T}_{\max }$, time to maximum plasma concentration $\mathrm{AUC}_{\text {in }}$, area under the plasma concentration versus time curve extrapolated to infinity; f (0-1), ratio of $\mathrm{AUC}_{0-1} / \mathrm{AUC}_{\text {inf }} ; \mathrm{t}_{1 / 2}$, halflife; $\mathrm{Cl} / \mathrm{F}$, oral clearance $(\mathrm{L} / \mathrm{h} / \mathrm{kg})$.

${ }^{a}$ Values are mean \pm SD. $P>.05$ for all parameters when captopril alone is compared with captopril with cephradine.

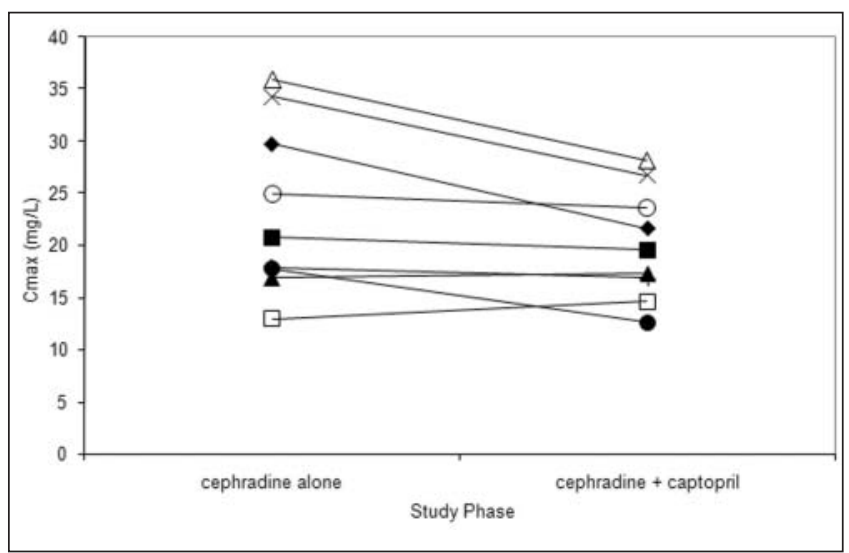

Figure 3. Change in cephradine $C_{\max }$ (maximum plasma cephradine concentration). Lines represent individual subject changes.

part, by the kidneys through glomerular filtration and tubular secretion. ${ }^{33,34}$ Although competition for renal re-absorption by means of renal transporters (eg, hPEPT1 and hPEPT2) could increase the renal clearance of the substrates when co-administered, there was no evidence of this in the present study.

Our hypothesis, that cephradine and captopril may compete for peptide transporters, was based on several prior observations. Cephradine is transported by means of hPEPT1 in cultured human intestinal cell monolayers, a process that is inhibited by oligopeptides and peptidomimetics. ${ }^{19,24,35}$ Intestinal perfusion studies in animals and studies using isolated intestinal membrane vesicles have demonstrated that ACE inhibitors are also transported by means of peptide transporters, and that their transport is competitively inhibited by oligopeptides and peptidomimetics, including cephalosporins. ${ }^{20-22}$ Similarly, in vitro investigations have described the saturable transport of ACE inhibitors by the renal peptide transporters hPEPT1 and hPEPT2. ${ }^{14}$ Jacolot and colleagues demonstrated that intra-intestinal administration of captopril in rats causes a marked increase in the half-life of the cephalosporin cefdinir. ${ }^{36}$ In a subsequent experiment, the same group administered cephalexin (a cephalosporin) and quinapril (an ACE inhibitor) to rats, using different routes of administration (ie, oral and parenteral administration). They found that while parenteral administration of quinapril did not alter the disposition of either orally or parenterally administered cephalexin, the co-administration of oral cephalexin and oral quinapril resulted in a 30\% decrease in cephalexin oral clearance and a $30 \%$ increase in cephalexin AUC. ${ }^{37}$ They also observed a decrease in the cephalexin absorption rate constant with oral quinapril, but no difference in the extent of absorption. They suggested that competition of cephalosporins and ACE inhibitors for active tubular secretion in the kidneys by means of a renal anionic transport system, as well as inhibition of active transport of cephalexin by quinapril in the intestine may be responsible for the observed pharmacokinetic behavior. ${ }^{16,38,39}$

Despite in vitro and animal studies suggesting the possibility of a significant interaction between cephradine and captopril, there are several plausible explanations for the lack of such an interaction in the current study. Based on the variability in our data, the number of subjects required to detect a $30 \%$ decrease in total captopril AUC when coadministered with cephradine is 8 (with a power of $80 \%$ and $\alpha=.05$ ). The corresponding sample size calculation to detect a $30 \%$ decrease in cephradine AUC when coadministered with captopril is 9. Therefore, we believe our study was adequately powered to detect what we consider clinically important differences. Although total captopril concentrations were still detectible in plasma samples at the end of our sampling strategy (10 hours), we do not believe this affected our ability to detect a potential interaction, as the primary mechanism of a potential interaction is likely to involve changes in absorption, which would be characterized by our sampling. Moreover, our sampling captured almost $90 \%$ of the total captopril AUC. Importantly, it is likely that multiple mechanisms are responsible for cephradine and captopril absorption in vivo, so that inhibition of a 
single route of permeation or single transporter (or even a single family of transporters), has a diluted effect. This phenomenon likely includes both active and passive transport mechanisms. For example, we demonstrated that the in vivo intestinal permeability of valacyclovir, a well known hPEPT1 substrate, correlates well with the intestinal expression of the transporter, HPT1, whereas correlation with hPEPT1 is poor. ${ }^{40}$ The role of HPT1 in the transport of other hPEPT1 substrates is currently under investigation; however, it is reasonable to speculate that there is inherent redundancy in peptide transporters. In this regard, it is interesting to note a recent study conducted to examine the potential for cephalexinvalacyclovir interactions in human subjects after oral co-administration of valacyclovir and cephalexin. The authors reported that co-administration of valacyclovir and cephalexin minimally affected the AUC of the parent drug acyclovir, suggesting minimal interaction between these hPEPT1 substrates. ${ }^{41}$ The authors indicate that the lack of interaction may suggest the possibility that cephalexin and valacyclovir are absorbed by means of other transporters and are less dependent on hPEPT1-mediated transport than previously suggested. ${ }^{41}$ It is also pertinent to note that transporter expression and distribution may be quite different in humans compared with animals and in vitro models.

Another factor that could explain the lack of interaction between cephradine and captopril is that the doses used may have been insufficient to saturate the existing transporters in vivo. The doses were chosen based on typical clinical doses of the 2 drugs. However, the Michaelis-Menton constants $\left(k_{m}\right)$ for cephradine and captopril absorption have been reported as $1.50 \mathrm{mM}$ and $5.91 \mathrm{mM}$, respectively. ${ }^{42}$ Although it is difficult to accurately estimate the precise volume in which an oral dosage form would be dissolved in vivo, the 500-mg dose of cephradine and the 25-mg dose of captopril corresponds to molar amounts of approximately 1.43 and 0.12 mmol, respectively. It is therefore quite possible that the concentrations of the drugs present in the intestinal lumen may have been substantially lower than those required to saturate the peptide transportermediated absorption process. Study drugs were administered in the fasted state, without standardization of prior dietary protein intake. Theoretically, this may have influenced our results. For example, studies conducted in rats indicate fasting for 24-48 hours may increase intestinal PEPT1 expression; it is unknown, however, whether this phenomenon occurs in humans, and, if so, whether the brief fast used in the present study (10 hours) would sufficiently impact hPEPT1 expression. ${ }^{43,44}$ Additionally, animal studies have suggested that high protein diets may result in increased expression of PEPT1, although this finding has not yet been confirmed in humans. ${ }^{45-47}$

The drugs used in this study, cephradine and captopril were not chosen because of any perceived likelihood that these compounds would be commonly coadministered clinically; rather, they were selected as representative substrates for aminocephalosporins and ACE inhibitors, respectively. To this end, captopril and cephradine are both well characterized PEPT1 substrates that have been shown to compete for PEPT1 (in both in vitro and animal experiments). ${ }^{48,49}$ Captopril also offered a practical advantage over other ACE inhibitors, because of its relatively short half-life (ie, this may limit the duration of any hypotensive effects in study subjects). It is unknown whether choosing alternative ACE inhibitor and cephalosporin substrates would produce similar results.

\section{CONCLUSIONS}

To the best of our knowledge, this is the first study examining the potential interaction between cephalosporins and ACE inhibitors in humans. In summary, co-administration of 2 peptidomimetic compounds, cephradine and captopril, did not result in clinically significant changes in the pharmacokinetics of cephradine or captopril, despite sharing common transport pathways in the small intestine and kidneys. Based on these results, co-administration of these hPEPT1 and hPEPT2 substrates is not likely to result in clinically important drug interactions; although it is unknown whether this conclusion can be generalized to other hPEPT1/hPEPT2 substrates, other studies support this premise. This apparent lack of propensity for transport-related drug interactions offers further support for the use of hPEPT1mediated transport as a means of improving oral drug absorption.

\section{ACKNOWLEDGMENTS}

Work was conducted at the University of Michigan. This study was approved by the University of Michigan Institutional Review Board. 


\section{REFERENCES}

1. Oh D-M, Han H-K, Amidon GL. Drug transport and targeting. In: Amidon GL, Sadee W eds. Membrane Transporters as Drug Targets. New York, NY: Klewer Academis/Plenum; 1999:59-88.

2. Eberl S, Renner B, Neubert A, et al. Role of p-glycoprotein inhibition for drug interactions:Evidence from in vitro and pharmacoepidemiological studies. Clin Pharmacokinet. 2007;46:1039-1049.

3. Callaghan R, Crowley E, Potter S, Kerr ID. P-glycoprotein: so many ways to turn it on. J Clin Pharmacol. 2008;48:365-378

4. Tsuji A, Tamai I. Carrier-mediated intestinal transport of drugs. Pharm Res. 1996;13:963-977.

5. Sai Y. Biochemical and molecular pharmacological aspects of transporters as determinants of drug disposition. Drug Metab Pharmacokinet. 2005;20:91-99.

6. Herrera-Ruiz D, Knipp GT. Current perspectives on established and putative mammalian oligopeptide transporters. J Pharm Sci. 2003;92:691-714.

7. Brodin B, Ielsen CU, Teffansen B, Fokjaer S. Transport of peptidomimetic drugs by the intestinal $\mathrm{Di} /$ tri-peptide transporter, PepT1. Pharmacol Toxicol. 2002;90:285-296.

8. Terada T, Inui KI. Peptide transporters: structure, function, regulation and application for drug delivery. Curr Drug Metab. 2004;5:85-94.

9. Anand BS, Patel J, Mitra AK. Interactions of the dipeptide ester prodrugs of acyclovir with the intestinal oligopeptide transporter: competitive inhibition of glycylsarcosine transport in human intestinal cell line-caco-2. J Pharmacol. 2003;2:781-791.

10. Irie M, Terada T, Sawada K, Saito H, Inui KI. Recognition and transport characteristics of nonpeptidic compounds by basolateral peptide transporter in caco-2 cells. J Pharmacol. 2001;298:711-717.

11. Lepsy CS, Guttendorf RJ, Kugler AR, Smith DE. Effects of organic anion, organic cation, and dipeptide transport inhibitors on cefdinir in the isolated perfused rat kidney. Antimicrob Agents Chemother. 2003;47:689-696.

12. Berger UV, Hediger MA. Distribution of peptide transporter PEPT2 mRNA in the rat nervous system. Anat Embryol (Berl). 1999;199:439-449.

13. Bahadduri PM, D'Souza VM, Pinsonneault JK, et al. Functional characterization of the peptide transporter PEPT2 in primary cultures of human upper airway epithelium. Am J Respir Cell Mol Biol. 2005;32:319-325.

14. Shu C, Shen H, Hopfer, U, Smith DE. Mechanism of intestinal absorption and renal reabsorption of an orally active ace inhibitor: uptake and transport of fosinopril in cell cultures. Drug Metab Dispos. 2001;29:1307-1315.

15. Lin CJ, Smith DE. Glycylsarcosine uptake in rabbit renal brush border membrane vesicles isolated from outer cortex or outer medulla: evidence for heterogeneous distribution of oligopeptide transporters. AAPS Pharm Sci. 1999;1:E1.

16. Lin JH, Chen IW, Ulm EH, Duggan DE. Differential renal handling of angiotensin-converting enzyme inhibitors enalaprilat and lisinopril in rats. Drug Metab Dispos. 1988;16:392-396.

17. Yuasa H, Fleisher D, Amidon GL. Noncompetitive inhibition of cephradine uptake by enalapril in rabbit intestinal brush-border membrane vesicles: an enalapril specific inhibitory binding site on the peptide carrier. J Pharmacol Exp Ther. 1994;269:1107-1111.

18. Yuasa H, Amidon GL, Fleisher D. Peptide carrier-mediated transport in intestinal brush border membrane vesicles of rats and rabbits: cephradine uptake and inhibition. Pharm Res. 1993;10:400-404.

19. Thwaites DT, Hirst BH, Simmons NL. Substrate specificity of the di/tripeptide transporter in human intestinal epithelia (Caco-2): identification of substrates that undergo $\mathrm{H}(+)$-coupled absorption. Br J Pharmacol. 1994;113:1050-1056.

20. Kitagawa $S$, Takeda J, Sato $S$. pH-dependent inhibitory effects of angiotensin-converting enzyme inhibitors on cefroxadine uptake by rabbit small intestinal brush-border membrane vesicles and their relationship with hydrophobicity and the ratio of zwitterionic species. Biol Pharm Bull. 1999;22:721-724.

21. Kitagawa S,Takeda J, Kaseda Y, Sato S. Inhibitory effects of angiotensin-converting enzyme inhibitor on cefroxadine uptake by rabbit small intestinal brush border membrane vesicles. Biol Pharm Bull. 1997;20:449-451.

22. Friedman DI, Amidon GL. Intestinal absorption mechanism of dipeptide angiotensin converting enzyme inhibitors of the lysyl-proline type: lisinopril and SQ 29,852. J Pharm Sci. 1989;78:995-998.

23. Friedman DI, Amidon GL. Passive and carrier-mediated intestinal absorption components of two angiotensin converting enzyme (ACE) inhibitor prodrugs in rats: enalapril and fosinopril. Pharm Res. 1989;6:1043-1047.

24. Matsumoto S, Saito H, Inui K. Transcellular transport of oral cephalosporins in human intestinal epithelial cells, Caco-2: interaction with dipeptide transport systems in apical and basolateral membranes. J Pharmacol Exp Ther. 1994;270:498-504.

25. Hu M, Zheng L, Chen J, et al. Mechanisms of transport of quinapril in Caco-2 cell monolayers: comparison with cephalexin. Pharm Res. 1995;12:1120-1125.

26. Zhu T, Chen XZ, Steel A, Hediger MA, Smith D. Differential recognition of ACE inhibitors in xenopus laevis oocytes expressing rat PEPT1 and PEPT2. Pharm Res. 2000;17:526-532.

27. Lukner P, Brandsch M. Interaction of $31 \beta$-lactum antibiotics with the $\mathrm{H}+$ /peptide symporter PEPT2: analysis of affinity constants and comparison with PEPT1. Eur J Pharm Biopharm. 2005;59:17-24

28. Moore VA, Irwin WJ, Timmins $P$, et al. A rapid screening system to determine drug affinities for the intestinal dipeptide transporter 2: affinities of ACE inhibitors. Int J Pharm. 2000;210:29-44.

29. Bathala MS, Weinstein SH, Meeker FS Jr, Singhvi SM, Migdalof BH. Quantitative determination of captopril in blood and captopril and its disulfide metabolites in plasma by gas chromatography. J Pharm Sci. 1984;73:340-344.

30. Drummer OH, Jarrot B, Louis WJ. Combined gas chromatographic-mass spectrometric procedure for the measurement of captopril and sulfur-conjugated metabolites of captopril in plasma and urine. J Chromatogr. 1984;305:83-93.

31. Lindgren K. Determination of cefadroxil in serum by highperformance liquid chromatography with cephradine as internal standard. J Chromatogr. 1987;413:347-350.

32. Gibaldi M, Perrier D. Pharmacokinetics. New York: Dekker; 1982:409-417.

33. Nightingale CH, Greene DS, Quintiliani R. Pharmacokinetics and clinical use of cephalosporin antibiotics. J Pharm Sci. 1975;64:1899-1926.

34. Duchin KL, McKinstry DN, Cohen AI, Migdalof BH. Pharmacokinetics of captopril in healthy subjects and in patients with cardiovascular diseases. Clin Pharmacokinet. 1988;14:241-259. 
35. Inui K, Yamamoto M, Saito H. Transepithelial transport of oral cephalosporins by monolayers of intestinal epithelial cell line Caco-2: specific transport systems in apical and basolateral membranes. J Pharmacol Exp Ther. 1992;261:195-201.

36. Jacolot A, Tod M, Petitjean O. Pharmacokinetic interaction between cefdinir and two angiotensin-converting enzyme inhibitors in rats. Antimicrob Agents Chemother. 1996;40:979-982.

37. Padoin C, Tod M, Perret G, Petitjean O. Analysis of the pharmacokinetic interaction between cephalexin and quinapril by a nonlinear mixed-effect model. Antimicrob Agents Chemother. 1998;42:1463-1469.

38. Bins JW, Mattie H. Saturation of the tubular excretion of betalactam antibiotics. Br J Clin Pharmacol. 1988;25:41-50.

39. van Ginneken CA, Russel FG. Saturable pharmacokinetics in the renal excretion of drugs. Clin Pharmacokinet. 1989;16:38-54.

40. Landowski CP, Sun D, Foster DR, et al. Gene expression in the human intestine and correlation with oral valacyclovir pharmacokinetic parameters. J Pharmacol Exp Ther. 2003;306:778-786.

41. Phan DD, Chin-Hong P, Lin ET, Anderle P, Sadee W, Guglielmo BJ. Intra- and interindividual variabilities of valacyclovir oral bioavailability and effect of coadministration of an hPEPT1 inhibitor. Antimicrob Agents Chemother. 2003;47:2351-2353.

42. Bai JPF, Stewart BH, Amidon GL. Gastrointestinal transport of peptide and protein drugs and prodrugs. In: Welling PG, Balant
LP, eds. Handbook of Experimental Pharmacology. Heidelberg: Springer-Verlag; 1994:189-206.

43. Naruhashi K, Sai Y, Tamai I, Suzuki N, Tsuji A. PepT1 mRNA expression is induced by starvation and its level correlates with absorptive transport of cefadroxil longitudinally in the rat intestine. Pharm Res. 2002;19:1417-1423.

44. Thamotharan M, Bawani SZ, Zhou X, Adibi SA. Functional and molecular expression of intestinal oligopeptide transporter (Pept-1) after a brief fast. Metabolism. 1999;48:681-684.

45. Erickson RH, Gum JR, Lindstrom MM, McKean D, Kim YS. Regional expression and dietary regulation of rat small intestinal peptide and amino acid transporter mRNAs. Biochem Biophys Res Commun. 1995;216:249-257.

46. Shiraga T, Miyamoto K, Tanaka H, et al. Cellular and molecular mechanisms of dietary regulation on rat intestinal $\mathrm{H}+/$ Peptide transporter PepT1. Gastroenterology. 1999;116:354-362.

47. Adibi SA. Regulation of expression of the intestinal oligopeptide transporter (Pept-1) in health and disease. Am J Physiol Gastrointest Liver Physiol. 2003;285:G779-G788.

48. Thwaites DT, Cavet M, Hirst BH, Simmons NL. Angiotensinconverting enzyme (ACE) inhibitor transport in human intestinal epithelial (Caco- 2) cells. Br J Pharmacol. 1995;114:981-986.

49. Hu M, Amidon GL. Passive and carrier-mediated intestinal absorption components of captopril. J Pharm Sci. 1988;77:1007-1011. 